\title{
Purinergic receptor activation evokes neurotrophic factor NPY release from neonatal mouse olfactory epithelial slices
}

\author{
Shami Kanekar ${ }^{1}$, Cuihong $\mathrm{Jia}^{2}$, and Colleen Cosgrove Hegg ${ }^{1,2}$ \\ ${ }^{1}$ Department of Physiology, University of Utah, Salt Lake City, UT 84108-1297 \\ ${ }^{2}$ Department of Pharmacology and Toxicology, Michigan State University, East Lansing, MI \\ 48824
}

\section{Abstract}

One premise regarding the mechanism of injury-evoked neuroregeneration is that injured cells induce the release of neurotrophic factors to trigger neurogenesis. Extracellular purine nucleotides exert multiple neurotrophic actions in the central nervous system mediated via activation of purinergic receptors. However, whether purinergics have a neurotrophic role in the olfactory neuroepithelium has not been investigated. Thus, we monitored the ATP-induced release of neuropeptide Y (NPY), a neuropeptide that increases neuroproliferation in the olfactory epithelium. To visualize NPY release, slices of olfactory epithelium from neonatal mice were cultured on nitrocellulose paper. Immunoassays of the nitrocellulose demonstrated NPY immunoreactivity in regions corresponding to the olfactory epithelium of the nasal cavity. One $\mathrm{hr}$ exposure to exogenous ATP $(100,500 \mu \mathrm{M})$ significantly increased the number of olfactory epithelium slices that released NPY from $25 \pm 6 \%$ to $60 \pm 7 \%$ or $71 \pm 10 \%$ ( $\mathrm{p}=0.001$ ). The purinergic receptor antagonists pyridoxalphosphate-6-azophenyl-2',4'-disulfonic acid (PPADS; $25 \mu \mathrm{M}$ ) and suramin $(100 \mu \mathrm{M})$ significantly reduced the number of olfactory epithelium slices exhibiting ATPevoked NPY release to $18 \pm 11 \%$ ( $\mathrm{p}=0.004)$, indicating that NPY release is mediated by activation of purinergic receptors. Released NPY was quantified by enzyme and radioimmunoassays. Exogenous ATP or UTP significantly increased the amount of NPY released. Collectively, this study demonstrates that purinergic receptor activation mediates the release of neurotrophic factor NPY in the olfactory epithelium and provides pharmacological targets to promote regeneration of damaged olfactory epithelium.

\section{Keywords}

ATP; regeneration; sustentacular cells; secretion; purinergic receptor antagonists

\section{Introduction}

The peripheral olfactory system is a good model to identify and study trophic factors that regulate neuroregeneration. During embryonic development and continuing through adulthood, olfactory sensory neurons (OSNs) are continuously renewed by neuronal progenitor cells called basal cells. Normally, in the mature olfactory epithelium, neurogenesis occurs to a small extent to replace a few OSNs that have been injured and are dying. The level of neurogenesis is tightly regulated by a multitude of chemical signals produced by the different cell types in the olfactory epithelium: the OSNs, sustentacular

Correspondence to be sent to: Colleen C. Hegg, Current address: Department of Pharmacology and Toxicology, Michigan State University, B439 Life Sciences Building, East Lansing, MI 48824, hegg@ msu.edu, (517) 432-2339 -office, (517) 353-8915 - fax. 
cells, and microvillar cells (Kawauchi et al., 2004; Mackay-Sim and Chuah, 2000).

However, when there is significant chemical, infectious or traumatic damage to the olfactory epithelium (OE), the rate of neurogenesis accelerates (Schwob, 2002). Dead and dying cells in the $\mathrm{OE}$ can release growth-promoting factors that initiate proliferation. We postulate that ATP, found in millimolar levels in all cells, is released by injured cells and acts as a positive regulator of neurogenesis by triggering localized neurotrophic factor release.

Extracellular purine nucleotides such as ATP exert multiple trophic actions in the central nervous system (Neary et al., 1996), including the synthesis and/or release of neurotrophic factors (Neary et al., 1996), stimulating proliferation and morphologic differentiation of a variety of cell types in vivo and in vitro (Rathbone et al., 1992a; Rathbone et al., 1999). The neurotrophic effects appear to be mediated via activation of G-protein coupled P2Y purinergic receptors and are possibly coupled to the production of inositol phosphates and other second messengers (Rathbone et al., 1992b). We have previously identified functional purinergic receptor expression in the olfactory system (Hegg et al., 2003). In general, OSNs express both the ionotropic $\mathrm{P} 2 \mathrm{X}_{1,4}$ receptors and the G-protein coupled $\mathrm{P} 2 \mathrm{Y}_{2}$ receptors, while the basal and sustentacular cells express the $\mathrm{P}_{2} \mathrm{Y}_{2}$ receptor subtype. Based on functional imaging, the A type adenosine purinergic receptors are not expressed in the $\mathrm{OE}$ (Hegg et al., 2003). Collectively, this indicates that purinergic receptors are ideally situated to have a role in both initiating and promoting injury-evoked proliferation in the OE.

NPY is a 36 amino acid peptide that mediates its action via 6 identified G-protein coupled $\mathrm{Y}_{1-6}$ receptors. In the peripheral olfactory system NPY is expressed in sustentacular cells (Hansel et al., 2001), a subpopulation of microvillar cells (Montani et al., 2006), and in olfactory ensheathing glia (OEGs) (Ubink et al., 1994). Moreover, the NPY $Y_{1}$ receptor is expressed in the basal cell layer where the neuronal progenitor cells are located (Hansel et al., 2001). NPY has been previously identified as a neuroproliferative factor in the mammalian OE (Hansel et al., 2001), in the subventricular zone of the lateral ventricle (Stanic et al., 2008), in hippocampal precursor cells (Howell et al., 2003; Howell et al., 2005), and in retinal Müller glial cells (Milenkovic et al., 2004). NPY acts through the $Y_{1}$ receptor to stimulate proliferation of adult olfactory neuronal progenitor cells (Hansel et al., 2001; Doyle et al., 2008) via activation of the extracellular signal-regulated kinase (ERK)1/2 cascade (Hansel et al., 2001). NPY deficient mice have a significant reduction in olfactory neuronal precursor proliferation (Hansel et al., 2001). Thus, NPY is a good candidate neurotrophic factor with which to test our hypothesis.

Our goal was to determine whether ATP activation of purinergic receptors evokes NPY secretion in the OE. The growth-promoting effects of ATP are usually mediated via the activation of G-protein coupled P2Y receptors (Di Virgilio, 2000). We used ATP, a P2X and P2Y receptor agonist, or UTP, a P2Y receptor agonist and found that both ATP and UTP could increase NPY secretion from OE slices and this effect was blocked by purinergic receptor antagonists. To our knowledge, neurotrophic factor secretion has not been directly measured in the OE. With this study, we have directly verified an important premise of neurogenesis in the $\mathrm{OE}$.

\section{Materials and Methods}

\section{Materials}

All chemicals were purchased from Sigma-Aldrich (St. Louis, MO) unless specified otherwise. 


\section{Mouse Olfactory Epithelium Slice Preparation}

All animal procedures were approved by the University of Utah or the Michigan State University Institutional Animal Care and Use Committees, and all applicable guidelines from the NIH Guide for Care and Use of Laboratory Animals were followed. Coronal olfactory epithelial slices $(500 \mu \mathrm{m})$ for NPY release experiments were prepared from postnatal day 1-3 Swiss Webster mice as previously described (Hegg et al., 2003). The number of slices obtained from each mouse pup ranged from 5-9.

To prepare tissue for immunohistochemistry, neonates were decapitated, the lower jaw was removed, the tissue was fixed by immersion in $4 \%$ paraformaldehyde overnight at $4{ }^{\circ} \mathrm{C}$, rinsed for $20 \mathrm{~min}$ in $0.1 \mathrm{M}$ phosphate buffered saline (PBS) and then cryoprotected with $30 \%$ sucrose. Tissue was oriented in Tissue Tek OCT (Sakura Finetek, Torrence, CA), quickly frozen and cryostat sections $(12 \mu \mathrm{m})$ were collected onto Superfrost Plus slides (Fisher, Pittsburgh, PA).

\section{Immunohistochemistry}

To determine if NPY was expressed in Swiss Webster neonatal mouse, tissue sections were processed for immunoreactivity to rabbit-anti mouse NPY antibody (1:50-1:150; T-4069, Bachem, Torrance, CA), goat anti-olfactory marker protein (OMP; 1:2,000, generous gift from F. Margolis; or 1:250, Waco Chemicals USA, Plano TX), rabbit anti-phospholipase C (PLC) 32 (1:50, SC-206, Santa Cruz Biotechnologies, Santa Cruz, CA), rabbit anti-Notch 2 (1:200, SC-5545, Santa Cruz Biotechnologies), or rabbit anti-calnexin (1:500, \#208880, Calbiochem/EMD Chemicals, Gibbstown, NJ). NPY immunoreactivity was amplified using a tyramide signal amplification kit coupled to Alexa-Fluor 488 (Molecular Probes, Eugene, OR) according to the manufacturer's instructions. For double-labeling of NPY and PLC $\beta 2$, Notch 2 or calnexin, the TSA amplification kit was used with the NPY primary antibody following manufacturers instructions, followed by PLC $\beta 2$, Notch 2 or calnexin antibody application (made in $0.3 \%$ triton X-100 in PBS) for 2-3 hrs at room temperature. TRITCconjugated donkey anti-rabbit antibody (1:100 (PLC $\beta 2)$ or 1:200 (Notch 2, calnexin); Jackson ImmunoResearch Labs, West Grove, PA) was applied for $1 \mathrm{hr}$ at room temperature. For double-labeling of NPY and OMP, the TSA amplification kit was not used and primary antibodies were applied as a mixture for $1 \mathrm{hr}$ at room temperature. TRITC-conjugated donkey anti-goat immunoglobin and Cy2-or FITC-conjugated donkey anti-rabbit immunoglobin secondary antibody (1:100; Jackson ImmunoResearch Labs, West Grove, PA) were applied as a mixture for $30 \mathrm{~min}$. Sections were mounted in glycerol or Vectashield mounting medium for fluorescence (Vector Labs, Burlingame, CA) and visualized on a Zeiss confocal LSM 510 argon-krypton laser scanner attached to an upright Zeiss Axioskop 2FS microscope (NPY alone and NPY + OMP; Zeiss, Thornwood, NY) or an Olympus FluoView 1000 laser scanning confocal microscope (NPY + PLC $\beta 2$, Notch 2 or calnexin; Olympus, Center Valley, PA). Alexa Fluor 488, FITC and Cy2 dye were excited at $488 \mathrm{~nm}$ and low pass filtered at $505 \mathrm{~nm}$, and TRITC dye was excited at 568 (Zeiss) or 543 (Olympus) $\mathrm{nm}$ and low pass filtered at $550 \mathrm{~nm}$. Sequential scanning was performed to minimize bleedthrough. Antibody specificity was tested by omitting the primary antibodies, the secondary antibodies, or by using a peptide neutralization protocol in which the NPY antibody $(0.04 \mathrm{mg} / \mathrm{ml})$ was combined with a 10 fold excess of NPY peptide $(0.4 \mathrm{mg} / \mathrm{ml}$; Supplemental Figure 1A, B). No immunoreactivity was observed in any of the controls. To examine if cross reactivity occurred as a result of double-labeling with both antibodies raised in rabbit, sections were first incubated with the NPY antibody using the TSA kit, followed by incubation with antibody dilution buffer (i.e, no second primary antibody) and then with TRITC-conjugated donkey anti-rabbit immunoglobin (supplemental Figure 1 C,D). No NPY-immunoreactivity was observed when tissue was excited at $543 \mathrm{~nm}$. 


\section{Detection of NPY release}

To detect the release of NPY from the olfactory epithelium, slices were cultured on nitrocellulose membrane, which binds proteins and peptides such as NPY, as previously described (Reimer et al., 1999). The nitrocellulose membrane ( $0.45 \mu \mathrm{m}$; GE Osmonics, Minnetonka, MN) was placed in a $35 \mathrm{~mm}$ petri dish in a minimal volume of Ringer's solution containing different treatments as listed below. Ringer's solution contained (in $\mathrm{mM}$ ): $140 \mathrm{NaCl}, 5 \mathrm{KCl}, 1 \mathrm{MgCl}_{2}, 2 \mathrm{CaCl}_{2}, 10 \mathrm{HEPES}, 10$-glucose at $\mathrm{pH} 7.4$ and 310 mOsm. Treatments consisted of Ringer's control or ATP $(10,100$ and $500 \mu \mathrm{M})$. Concentrated stocks of ATP were made in Ringer's solution and kept frozen. On the day of the experiment, appropriate volumes of ATP stock solution were diluted to the final concentration in the Ringer's solution. In some experiments, slices were pretreated with the non-specific purinergic receptor (P2) antagonists pyridoxalphosphate-6-azophenyl-2',4'disulfonic acid (PPADS; $25 \mu \mathrm{M})$ and suramin $(100 \mu \mathrm{M})$ for 5 min before ATP was added. Because both suramin and PPADS act as partial antagonists on many of the purinergic receptor subtypes (Ralevic and Burnstock, 1998) expressed in the OE, we were conservative and applied both antagonists in this study. The concentration and duration of PPADS and suramin pre-application were previously shown to block ATP-induced increases in intracellular calcium in the OE slice preparation (Hegg et al., 2003), and a 30 minute preinjection of both purinergic receptor antagonists was previously shown to inhibit ATPinduced heat shock protein expression in vivo (Hegg and Lucero, 2006). A concentrated stock solution of both PPADS and suramin was kept at $4{ }^{\circ} \mathrm{C}$ and diluted directly in the Ringer's solution with the nitrocellulose membrane.

All olfactory epithelial slices obtained from a single mouse were placed directly on the nitrocellulose paper and left for $1 \mathrm{hr}$ at room temperature. Great care was taken to place the slice so all areas made direct contact with the nitrocellulose. For all treatment groups, the slices were removed from the nitrocellulose membrane after $1 \mathrm{hr}$ and the membrane was airdried. As a positive staining control, NPY (100-250 nM; Bachem, Torrance, CA) was dotted onto one corner of the nitrocellulose membrane and allowed to dry. Nitrocellulose was vapor-fixed in $4 \%$ formaldehyde at $75^{\circ} \mathrm{C}$ for $2 \mathrm{hrs}$ (Reimer et al., 1999). The nitrocellulose membrane was incubated for $1 \mathrm{hr}$ with 5\% tween 20 and 5\% carnation lowfat milk in phosphate buffered saline to block non-specific staining, and then incubated with rabbit antimouse NPY antibody (Bachem, Torrance, CA; 1:150 in 5\% tween 20 and 5\% carnation lowfat milk in phosphate buffered saline) at $4^{\circ} \mathrm{C}$ overnight. NPY immunoreactivity was visualized using a Vectastain ABC kit (Vector Laboratories, Burlingame, CA) and 3,3',5,5' tetramethylbenzidine (TMB; Pierce, Rockford IL). All blots were processed with TMB with equal staining times. Positive staining controls indicated that this protocol could detect as low as $4 \mathrm{pg}$ NPY bound to nitrocellulose. Omission of the primary antibody for NPY or using the peptide neutralization protocol described above exhibited no immunoreactivity (data not shown).

Immunoblots were scanned and the resultant digital images were adjusted by altering the contrast and brightness such that the digital images looked like the original blots by eye. In all instances, the same adjustments were made to all images from blots generated on the same experimental day. Two investigators, blinded to the treatments, tabulated the number of slices with intense NPY immunoreactivity in the olfactory epithelial regions. Intense immunoreactivity was defined in this experiment as greater than $25 \%$ of background level seen under the slice and was determined using ImageJ software (Rasband, W.S., ImageJ, U. S. National Institutes of Health, Bethesda, MD, USA, http://rsb.info.nih.gov/ij/, 1997-2007). The percentage of slices releasing NPY was determined for each experiment and is expressed as mean \pm s.e.m. For each treatment, the experiments were repeated 3-10 times. 
To quantify NPY immunoreactivity, we measured the integrated density of the immunoreactivity from each slice on the nitrocellulose using ImageJ software. Scanned images were inverted, regions of interest were positioned around the area where slices had been placed, and integrated density was measured. Data were corrected for background by subtracting the integrated density from a region where a slice had not been placed. A dot blot with known amounts of applied NPY peptide (1-500 nM) was analyzed similarly and a standard curve was generated. Integrated densities of NPY immunoreactivity from the slices were in the linear range of the concentration response relationship (data not shown). Data were normalized to the control Ringer's group ( $0 \mu \mathrm{M}$ ATP) for each date on which the experiment was performed, and is expressed as average normalized integrated density \pm s.e.m.

\section{Quantification of NPY release}

For quantification of NPY release, all $500 \mu \mathrm{m}$ coronal olfactory epithelial slices from a single mouse were placed in Ringer's solution at room temperature (1 hr time point) or tissue culture medium (DMEM/F12, $100 \mathrm{U} / \mathrm{ml}$ penicillin $\mathrm{G}$ and $100 \mathrm{mg} / \mathrm{ml}$ streptomycin; Invitrogen, Carlsbad, CA) at $37^{\circ} \mathrm{C}$ and $5 \% \mathrm{CO}_{2}$ ( $24 \mathrm{hr}$ time point only). Either ATP (10, 100 or $500 \mu \mathrm{M})$, or UTP $(100 \mu \mathrm{M})$ were added. After 1 or $24 \mathrm{hrs,} \mathrm{conditioned} \mathrm{media} \mathrm{were}$ collected and stored at $-80^{\circ} \mathrm{C}$. Levels of NPY in the media were assayed initially using a radioimmunoassay (RIA) kit (Phoenix Pharmaceuticals, Belmont, CA). Data were collected with a Wallac 1470 wizard gamma counter (Perkin Elmer Life Sciences, Turku, Finland). All samples were run in duplicate, and averaged. Unconditioned medium not exposed to tissue was collected as control, and consistently showed undetectable levels of NPY (data not shown). Addition of PPADS and suramin to the unconditioned media in the absence of tissue interfered with the RIA results, giving a false positive readout of ca. $200 \mathrm{pg} / \mathrm{ml}$ NPY. Thus, we performed parallel experiments using an enzyme immunoassay (EIA) kit (Phoenix Pharmaceuticals, Belmont, CA) and a $\mu$ Quant Microplate Spectrophotometer (Bio-tek Instruments, Inc., Winooski, VT), and observed similar false positive readings from PPADS and suramin controls. This suggests that the antagonists interact with a component of the immunoassay kits to cause a false positive reading. As a result, we were unable to quantify the level of NPY released in the presence of PPADS and suramin.

\section{Statistical analyses}

For all statistical analysis, $\mathrm{n}=$ number of mice used for each treatment. Statistical significance was determined with GraphPad Prism 5.01 software (San Diego, CA) using a one-way analysis of variance (ANOVA). If the ANOVA $p$ value was $p<0.05$, then the posthoc Tukey's multiple comparison test was performed for all possible pairwise comparisons. For the quantification of NPY release, we examined the effect of time and ATP concentration on NPY release, and thus also performed a two-way repeated measures ANOVA.

\section{Results}

\section{Expression of NPY in the neonatal mouse OE}

Presence of NPY has been reported in the olfactory epithelium in both sustentacular cells (Hansel et al., 2001) and microvillar cells (Montani et al., 2006) of adult rodents. In this study we show that NPY is expressed in the olfactory epithelium of neonatal Swiss Webster mice. In general, we observed two types of NPY immunoreactivity (IR) in the apical region of the OE: intense IR in a subset of cells found in the dorsal medial meatus and dorsal region of the septal OE, and diffuse staining found in the endo- and ecto-turbinates (Figure $1 \mathrm{~A}$ ). NPY-IR was not observed when the antibody was preadsorped with NPY peptide (Supplemental Figure 1 A,B). 
Intense NPY-IR was observed in cells that were morphologically similar to sustentacular cells with a prominent cell soma in the upper third of the OE, and a thin cytoplasmic extension that terminates in an endfoot process at the basal lamina (Graziadei, 1971) (Figure $1 \mathrm{~B}, \mathrm{C})$. We also observed cells with intense NPY immunoreactivity that were morphologically similar to the microvillar cells, a flask shaped cell soma located apically in the OE with a basal process (Figure $1 \mathrm{~B}$ ). To determine the identity of the $\mathrm{NPY}^{+}$cells, we performed double-labeling with antibodies directed against the microvillar cell marker PLC 32 (Elsaesser et al., 2005), and the sustentacular cell markers calnexin (Czesnik et al., 2006) and Notch 2 (Carson et al., 2006). Intense NPY-IR was observed in a subset of PLC $\beta 2^{+}$microvillar cells (Figure $1 \mathrm{D}, \mathrm{E}$ ), as well as in a subset of calnexin ${ }^{+}$cells (Figure 1 G) and Notch $2^{+}$cells (Figure 1 I). Control experiments indicated that there was no crossreactivity using the antibodies raised in the same species (refer to Methods; Supplemental Figure $1 \mathrm{C}, \mathrm{D})$. NPY immunoreactivity did not occur in mature olfactory sensory neurons identified by the selective olfactory marker protein (OMP) (Figure $1 \mathrm{~F}$ ). We also observed intense NPY immunoreactivity in the olfactory ensheathing glia that surround the axons of OSNs as they travel from the olfactory epithelium to the glomeruli in the olfactory bulb and in Bowman's gland duct cells of the lamina propria (Figure 1 B,E, F). However, the intensity of NPY-IR in the lamina propria was diminished with longer washing conditions (Supplemental Figure 1 E,F). Diffuse NPY-IR was confined to the calnexin ${ }^{+}$sustentacular cells located on the endo- and ecto- turbinates (Figure $1 \mathrm{H}$ ). These data indicate that NPY is restricted to the sustentacular and microvillar cells in the peripheral olfactory epithelium and to the olfactory ensheathing glia and Bowman's gland duct cells in the lamina propria of the neonatal mouse $\mathrm{OE}$.

\section{Visualization of ATP-evoked NPY secretion}

To visualize NPY secretion, we placed OE slices (Figure 2 A) on nitrocellulose membranes for $1 \mathrm{hr}$ in the presence of different treatments and then processed the nitrocellulose for immunoreactivity against NPY. When primary antibody for NPY was omitted, no immunoreactivity was seen (data not shown). In the absence of exogenously added ATP (0 $\mu \mathrm{M})$, we observed low level background NPY immunoreactivity that varied in intensity but delineated the location of each slice on the nitrocellulose in all of the OE slices ( $\mathrm{n}=82$ slices, 10 animals; Figure 2 B,C). This background NPY immunoreactivity was $25 \pm 6 \%$ more intense than from a similar area without a slice $(n=10$ animals). This observation suggests that NPY and/or ATP (subsequently evoking NPY release) is either tonically secreted or released from cells damaged during the slicing procedure. Further, in this control $(0 \mu \mathrm{M}$ ATP) group, we also observed robust immunoreactivity for NPY in the septal OE in $25 \pm 6 \%$ of the OE slices ( $n=18$ NPY-IR +82 total slices, 10 animals; Figure $2 \mathrm{C}$ ). NPY immunoreactivity was never seen in the respiratory epithelial regions. When the OE slices were exposed to 10,100 or $500 \mu \mathrm{M}$ ATP, the number of slices that exhibited robust NPY immunoreactivity in the olfactory regions was significantly increased to $52 \pm 9 \%(\mathrm{n}=19$ NPY-IR +41 total slices, 6 animals), $60 \pm 7 \%\left(\mathrm{n}=21 \mathrm{NPY}-\mathrm{IR}^{+} / 37\right.$ total slices, 6 animals), and $71 \pm 10 \%\left(\mathrm{n}=14 \mathrm{NPY}-\mathrm{IR}^{+} / 20\right.$ total slices, 4 animals) respectively ( $\mathrm{p}=0.001$, one way ANOVA; Figure 2 D-M). These results indicate that ATP stimulates the release of NPY from the OE.

To determine whether the effect of ATP on NPY release in the OE is mediated through purinergic receptor activation, $\mathrm{OE}$ slices were pretreated with the $\mathrm{P} 2$ receptor antagonists PPADS and suramin prior to co-incubation with ATP and PPADS and suramin. Treatment with P2 receptor antagonists alone evoked NPY immunoreactivity in $28 \pm 5 \%$ of the slices $\left(\mathrm{n}=13 \mathrm{NPY}-\mathrm{IR}^{+} / 43\right.$ total slices, 5 animals), similar to that seen in control Ringer's solution ( $25 \pm 6 \% ; \mathrm{n}=18 \mathrm{NPY}-\mathrm{IR}^{+} / 82$ total slices, 10 animals) (Figure $2 \mathrm{~N}$ ). Co-incubation of P2 receptor antagonists PPADS and suramin with $100 \mu \mathrm{M}$ ATP significantly reduced the ATP- 
induced increase in NPY immunoreactivity back to control levels $(18 \pm 11 \% ; \mathrm{n}=5 \mathrm{NPY}-$ $\mathrm{IR}^{+} / 29$ total slices, 4 animals; $\mathrm{p}=0.004$; Figure $2 \mathrm{~N}$ ), suggesting that the increase in the number of slices exhibiting NPY release is mediated through purinergic receptor activation.

We tabulated the regions of the OE that exhibited intense NPY-IR in rostral-, medial-, and caudal-situated slices (Table 1). In general, there were no differences in location of NPYsecretion from animal to animal (data not shown). NPY-IR was observed in $10 \%$ of the total rostral slices, $50 \%$ of the total medial slices and $44 \%$ of the total caudal slices. ATP or purinergic receptor antagonists did not alter the expression profile of NPY-IR from the rostral to caudal axis. Of the rostral slices, 50\% exhibited NPY-IR in the septum (similar to Figure $2 \mathrm{~K}$ ) and 50\% exhibited NPY-IR in the dorsal medial meatus (similar to Figure $2 \mathrm{H}$ ). Likewise, with the medial slices, 50\% had NPY-IR in the septum, $45 \%$ in the dorsal medial meatus, and 5\% in the turbinate (similar to Figure 2 I). The caudal situated slices exhibited NPY-IR in the septum (22\%) and the dorsal medial meatus (78\%). These results correlate well with the immunohistochemical study of NPY expression (Figure $1 \mathrm{~A}$ ) and suggest that NPY secretion occurs preferentially in the medial and caudal portions of the OE in the septum and dorsal medial meatus.

To quantify the release of NPY, we measured the integrated density of the immunoreactivity from each slice placed on the nitrocellulose. The measured integrated density significantly increased with concentration of ATP. Compared to $0 \mu \mathrm{M}$ ATP control ( $\mathrm{n}=82$ slices from 10 animals), ATP $(10,100$ and $500 \mu \mathrm{M})$ increased the NPY immunoreactivity by $8 \pm 3 \%, 32 \pm$ $7 \%$, and $38 \pm 10 \%$ (mean \pm s.e.m.) respectively ( $\mathrm{n}=41$ slices from 6 animals, 37 slices from 6 animals, 20 slices from 4 animals, respectively, Figure 3 A, p<0.0001; one way ANOVA). Significant differences were also observed in immunoreactivity density in the presence of ATP and purinergic receptor antagonists (one-way ANOVA, $\mathrm{p}=0.007$ ). When slices were exposed to only the $\mathrm{P} 2$ receptor antagonists PPADS and suramin, no significant change in integrated density was seen relative to control Ringer's solution $(88 \pm 18 \%, \mathrm{n}=13$ NPY$\mathrm{IR}^{+} / 43$ total slices, 5 animals, p>0.05 Tukey's post-hoc test, Figure $3 \mathrm{~B}$ ). However, coincubation of $100 \mu \mathrm{M}$ ATP with $\mathrm{P} 2$ receptor antagonists significantly reduced the integrated density back to control levels ( $93 \pm 6 \%$, compare with $132 \pm 7 \%$ for $100 \mu \mathrm{M}$ ATP; $\mathrm{n}=5$ NPY-IR ${ }^{+} / 29$ total slices, 4 animals, p>0.05 Tukey's post-hoc test, Figure 3 B). Thus, integrated density analysis of NPY blots supported and extended the results obtained from counting the number of slices releasing NPY. Both analyses confirmed that ATP exposure increases NPY release from slices, and that the ATP-evoked release is mediated through purinergic receptor activation.

\section{Quantification of ATP-evoked NPY release}

In the absence of OE slices, Ringer's solution or media alone and with ATP or UTP showed no detectable levels of NPY in both RIA and EIA assays (data not shown). However, the presence of PPADS and suramin gives a false positive result for NPY, thus rendering it impossible to detect the effect of P2 receptor activation on levels of NPY released in these experiments (see methods). We therefore quantified ATP-evoked NPY release using these immunoassays only for experiments performed without the use of the $\mathrm{P} 2$ receptor antagonists.

Slices were placed in Ringer's solution in the absence or presence of ATP (10, 100 or 500 $\mu \mathrm{M})$ or UTP $(100 \mu \mathrm{M})$ for $1 \mathrm{hr}$. The concentration of NPY released was measured using a RIA immunoassay (Figure 4A) and an EIA immunoassay (Figure 4B); only the EIA data will be described in the results (see figure legend for RIA data). Addition of OE slices to the control Ringer's solution induced $51 \pm 13 \mathrm{pg} / \mathrm{ml}$ NPY to be secreted (Figure 4; $\mathrm{n}=5$ animals, $\sim 30$ slices), and confirms our previous observation of faint NPY immunoreactivity in our nitrocellulose assay (Figure $2 \mathrm{~B}$ ). Possible explanations for this observation include 
(1) tonic release of exogenous ATP (Hegg et al., 2003) evokes NPY secretion, and/or (2) ATP or NPY is released from damaged cells during tissue sectioning. To test these hypotheses, apyrase ( $3 \mathrm{U} / \mathrm{ml})$, an enzyme that rapidly degrades ATP, was added to Ringer's solution and slices for $1 \mathrm{hr}$. Apyrase significantly reduced the concentration of NPY released to $14 \pm 2 \mathrm{pg} / \mathrm{ml}$ (Figure 4B; $\mathrm{p}=0.01, \mathrm{n}=3$ animals, $\sim 15$ slices), suggesting that ATP released tonically or from damaged cells evokes NPY release. Addition of ATP $(10,100,500 \mu \mathrm{M})$ significantly evoked NPY secretion of $72 \pm 18,87 \pm 21$, or $110 \pm 13 \mathrm{pg} / \mathrm{ml}$, respectively (Figure 4B; $\mathrm{p}<0.0001$, one way ANOVA, $\mathrm{n}=\sim 30$ slices from 5 animals in each treatment).

While we predict NPY secretion to occur quickly (10 min), ATP-evoked increases in neurotrophic factor synthesis could occur $10-15 \mathrm{hrs}$ after purinergic receptor activation. We therefore also quantified NPY release during a $24 \mathrm{hr}$ exposure to ATP. In the absence of ATP, OE slices released $65 \pm 2 \mathrm{pg} / \mathrm{ml}$ NPY ( $\mathrm{n}=3$; Figure 4B). Incubation of slices with ATP significantly evoked the release of $81 \pm 8,86 \pm 7$, or $88 \pm 5 \mathrm{pg} / \mathrm{ml}$, respectively (Figure $4 \mathrm{~B}, \mathrm{p}=0.03$, one way ANOVA, $\mathrm{n}=3$ animals, $\sim 18$ slices). We performed a two-way ANOVA examining the effects of time and concentration on NPY secretion and found no significant interaction between time and NPY concentration ( $\mathrm{p}=0.9)$, but did see significant effects with ATP concentration and NPY concentration ( $\mathrm{p}=0.04)$. In a few experiments, we examined the effect of the P2Y receptor agonist UTP $(100 \mu \mathrm{M})$ at $24 \mathrm{hrs}$ and measured 163 $\pm 35 \mathrm{pg} / \mathrm{ml}$ NPY, a significant increase over control (Figure 4B; $\mathrm{p}<0.05, \mathrm{n}=3$ animals, $\sim 18$ slices). This suggests that the ATP-induced increase in NPY release from OE slices likely occurs through a $\mathrm{P} 2 \mathrm{Y}$ receptor-mediated pathway.

\section{Discussion \\ Expression of NPY}

In the peripheral olfactory system of neonatal Swiss Webster mice, NPY-immunoreactivity is present in sustentacular cell and microvillar cell somas and distal processes in the olfactory epithelium and in the olfactory ensheathing glia and Bowman's gland duct cells of the lamina propria, a thin layer of loose connective tissue which lies beneath the epithelium and contains capillaries, glands, the axons of the OSNs, and olfactory ensheathing glia. Previous studies have shown that localization of NPY in the peripheral olfactory system differs across species and through development. In the mouse, Montani and colleagues (Montani et al., 2006) demonstrated NPY expression both in the basal cells beginning at embryonic day 16, and in the microvillar cells with expression starting during the first three postnatal weeks. NPY expression steadily increased until adulthood, where NPY expression remained exclusively localized to a subpopulation of microvillar cells. NPY expression has also been demonstrated in the adult mouse olfactory ensheathing glia (OEGs) that surround the axons of OSNs as they travel from the olfactory epithelium to the glomeruli in the olfactory bulb (Ubink et al., 1994). In the rat, embryonic expression of NPY occurs in the OSNs, basal cells (Hansel et al., 2001), and the OEGs (Ubink and Hokfelt, 2000). By adulthood the expression of NPY in the rat occurs in a subpopulation of sustentacular cells (Hansel et al., 2001) and in the OEGs (Ubink et al., 1994). NPY has also been reported in the peripheral olfactory system of non-mammalian species including cells in the olfactory organ of the embryonic and adult zebrafish (Mathieu et al., 2002), and in OSNs and basal cells in an adult teleost (Gaikwad et al., 2004).

The differences in NPY localization in mammalian species could be due to either strain differences, or due to different detection methods. In this study, in the mammalian neonate, we found NPY immunoreactivity in both the sustentacular and microvillar cells, whereas others have reported NPY immunoreactivity only in the microvillar cells (Montani et al., 2006). NPY immunoreactivity was detected in the sustentacular cells when tyramide signal amplification immunohistochemistry was performed (current study and Hansel et al., 2001), 
implying that sustentacular cells might express a lower level of NPY that requires amplification of the antigen (not the signal) to reveal immunoreactivity. Our study verifies and complements the previous studies investigating mammalian neonatal NPY expression.

\section{NPY release in the olfactory epithelium}

To determine if ATP and purinergic receptor activation triggers the release of neurotrophic factors in the OE, we measured ATP-induced secretion of NPY by a variety of techniques. Using an immunoblot technique to visualize NPY release, we observed a low level of immunoreactivity in the absence of exogenous ATP. Interestingly, we also observed very robust NPY immunoreactivity in $25 \%$ of the slices in control conditions (absence of ATP). These observations were substantiated by the quantification of 59 or $68 \mathrm{pg} / \mathrm{ml}$ NPY released from OE slices in a 1 or $24 \mathrm{hr}$ period in the absence of ATP. This could result from release of NPY and/or ATP from tissue damaged during the slicing, or from the tonic release of ATP (Hegg et al., 2003) or NPY. Use of apyrase, an ATP-degrading enzyme, significantly reduced NPY secretion in control conditions indicating that endogenously released ATP does play a role in NPY secretion.

In general, there was a trend for ATP to increase NPY secretion. With the addition of exogenous ATP $(10-500 \mu \mathrm{M})$, we observed both an increase in the number of slices that exhibited NPY release as well as the amount of secreted NPY. ATP-evoked increases in NPY secretion begins to plateau at $100 \mu \mathrm{M}$ ATP. Using calcium imaging, we previously reported an $\mathrm{EC}_{50}$ of $1.4 \mu \mathrm{M}$ ATP for cultured mouse OSNs with a concentration-response profile that plateaus at $5 \mu \mathrm{M}$ ATP (Hegg et al., 2003). In the present study we utilized 300$500 \mu \mathrm{m}$ OE slices rather than primary cell culture, which may be responsible for the shift in the concentration-response relationship. Mouse OSNs express both ionotropic P2X and Gprotein coupled P2Y receptors while sustentacular cells, the cells that contained NPY, express only the P2Y receptors (Hegg et al., 2003), which could also account for the differences in the concentration-response relationship. We measured NPY secretion from $300-500 \mu \mathrm{m}$ slices that subsequently diffused into the culture media, thus, we predict that the tissue levels of stimulated NPY release are much higher than what we measured in the cell media.

Robust ATP-induced NPY immunoreactivity was visualized in the olfactory specific regions of the nasal cavity, predominantly in medial and caudal-situated slices in either the septum region, or the dorsal medial meatus. A possible reason for this variability in immunoreactivity in the immunoblots could be due to the well documented phenomenon of zonal expression of phenotypic markers in the olfactory system. Odorant receptors are expressed in distinct anatomical regions that are bilateral and symmetric in nature (Ressler et al., 1993; Vassar et al., 1993). Metallothioneins and P450 biotransformation enzymes are diversely expressed in subsets of sustentacular cells, olfactory neurons, and in acinar cells of the Bowman's glands (Miyawaki et al., 1996; Skabo et al., 1997; Whitby-Logan et al., 2004). There is a zonal distribution of antigenically distinct progenitor cells (Murdoch and Roskams, 2008). Finally, NPY is expressed in subsets of microvillar cells (Montani et al., 2006) and sustentacular cells of the adult olfactory epithelium (Hansel et al., 2001). In the present study, we show that NPY is differentially expressed in specific areas in the neonatal mouse. For this reason, we used the entire olfactory epithelium from each animal in all experiments. It has been previously been reported that NPY expression occurred in $40 \%$ (2/5) of the post-natal day 5 mice (Montani et al., 2006), however, in our studies we never observed an absence in NPY-immunoreactivity from a single animal.

In the central nervous system, ATP evokes both the release of neurotrophic factors, a fast event (min), and the synthesis of neurotrophic factors, a slower event (hrs-days) (Neary et al., 1996). To determine if ATP evokes the release and the synthesis of NPY, we quantitated 
the amount of NPY following $1 \mathrm{hr}$ and $24 \mathrm{hr}$ ATP exposure. The two-way ANOVA examining the effects of time and concentration on NPY secretion indicated no significant differences between NPY secretion at 1 and $24 \mathrm{hrs,} \mathrm{although} \mathrm{the} \mathrm{concentration} \mathrm{of} \mathrm{ATP} \mathrm{does}$ significantly increase NPY release. These data imply that ATP evokes the release of NPY, but not the synthesis. A detailed in vivo immunohistochemical examination of the role of exogenous ATP on NPY synthesis will be important to distinguish ATP's role on NPY synthesis.

We show that ATP significantly increases the secretion of NPY through a mechanism that involves purinergic receptor activation. Use of purinergic receptor antagonists reduced the number of slices that exhibited ATP-evoked NPY release as well as the density of NPY immunoreactivity. Previous calcium imaging studies showed that the mouse OE slice does not respond to ATP degradation products such as ADP, AMP, and adenosine that activate the $\mathrm{P} 1$ purinergic receptors, suggesting that it is activation of the $\mathrm{P} 2$ purinergic receptors that mediates increased NPY release. Further, exposure to the G-protein coupled P2Y receptor agonist UTP also increases the secretion of NPY.

We previously found that sustentacular cells express only the P2Y receptor subtype (Hegg et al., 2003). Activation of $\mathrm{P} 2 \mathrm{Y}$ receptors on sustentacular cells evokes intracellular calcium increases that are mediated by phospholipase $\mathrm{C}$ activation of $\mathrm{IP}_{3}$ and subsequent release of calcium from internal stores. We have also observed ATP-induced increases in intracellular calcium in cells with the same morphology as microvillar cells (Hegg, unpublished observations), although we have not definitively identified specific expression of purinergic receptors in the microvillar cells. OEGs express the $\mathrm{P}_{2} \mathrm{Y}_{1}$ receptor subtype (Rieger et al., 2007). P2Y receptor-mediated increases in intracellular calcium may evoke calciumdependent exocytosis of vesicles containing NPY and other putative neurotrophic factors located either in the endfoot processes of sustentacular cells or in OEGs. Experiments are underway to determine the exact mechanism of NPY secretion.

\section{Possible Function of NPY in the olfactory epithelium}

Expression of NPY in different cell types indicates that NPY may have many different functions. NPY has been shown to be a neuromodulator in the olfactory epithelium of salamander (Mousley et al., 2006). NPY expression in the OEGs during development has been suggested to function in the final outgrowth of neurites as they travel to the olfactory bulb (Ubink and Hokfelt, 2000). NPY increases the proliferation of neuronal precursor cells derived from the olfactory epithelium suggesting a role in neuroregeneration (Hansel et al., 2001), and it has been suggested that NPY presence in sustentacular cells (Hansel et al., 2001) and microvillar cells (Montani et al., 2006) contributes to this neuroregeneration. This hypothesis was further supported by the observation that the NPY $\mathrm{Y}_{1}$ receptor is present on the neuronal precursor cells, and that basal cell proliferation can be mediated in vivo by a NPY $Y_{1}$ receptor agonist (Hansel et al., 2001).

The present study extends the previous reports regarding the function of NPY in microvillar and sustentacular cells. We demonstrate that ATP, a signal of cellular stress (Hegg and Lucero, 2006), can evoke the release of NPY, a neuroproliferative factor. Although our studies were unable to distinguish whether the source of released NPY was the sustentacular cells, the microvillar cells, or from the lamina propria, the presence of NPY in these cell types indicates they both could have a role in the neuroregeneration that occurs in the OE. This study was conducted in the neonate, and in the OE, neurogenesis continues throughout adulthood. Thus, future studies will examine whether ATP evokes NPY release in the adult mouse. To our knowledge, neurotrophic factor secretion has not been directly measured in the OE; thus, we have directly verified an important premise of neurogenesis in the OE. 


\section{Supplementary Material}

Refer to Web version on PubMed Central for supplementary material.

\section{Acknowledgments}

This work was supported by NIH DC006897 (CCH) and by Michigan State University Institutional Funds (CCH).

\section{References}

Carson C, Murdoch B, Roskams AJ. Notch 2 and Notch 1/3 segregate to neuronal and glial lineages of the developing olfactory epithelium. Dev Dyn. 2006; 235:1678-1688. [PubMed: 16518823]

Czesnik D, Kuduz J, Schild D, Manzini I. ATP activates both receptor and sustentacular supporting cells in the olfactory epithelium of Xenopus laevis tadpoles. Eur J Neurosci. 2006; 23:119-128. [PubMed: 16420422]

Di Virgilio F. Dr. Jekyll/Mr. Hyde: the dual role of extracellular ATP. J Auton Nerv Syst. 2000; 81:59-63. [PubMed: 10869701]

Doyle KL, Karl T, Hort Y, Duffy L, Shine J, Herzog H. Y1 receptors are critical for the proliferation of adult mouse precursor cells in the olfactory neuroepithelium. J Neurochem. 2008; 105:641-652. [PubMed: 18088353]

Elsaesser R, Montani G, Tirindelli R, Paysan J. Phosphatidyl-inositide signalling proteins in a novel class of sensory cells in the mammalian olfactory epithelium. Eur J Neurosci. 2005; 21:2692-2700. [PubMed: 15926917]

Gaikwad A, Biju KC, Saha SG, Subhedar N. Neuropeptide Y in the olfactory system, forebrain and pituitary of the teleost, Clarias batrachus. J Chem Neuroanat. 2004; 27:55-70. [PubMed: 15036363]

Graziadei, PPC. The Olfactory Mucosa of Vertebrates. In: Beidler, LM., editor. Handbook of Sensory Physiology. Berlin: Springer-Verlag; 1971. p. 27-58.

Hansel DE, Eipper BA, Ronnett GV. Neuropeptide Y functions as a neuroproliferative factor. Nature. 2001; 410:940-944. [PubMed: 11309620]

Hegg CC, Greenwood D, Huang W, Han P, Lucero MT. Activation of purinergic receptor subtypes modulates odor sensitivity. J Neurosci. 2003; 23:8291-8301. [PubMed: 12967991]

Hegg CC, Lucero MT. Purinergic receptor antagonists inhibit odorant-induced heat shock protein 25 induction in mouse olfactory epithelium. Glia. 2006; 53:182-190. [PubMed: 16206165]

Howell OW, Doyle K, Goodman JH, Scharfman HE, Herzog H, Pringle A, Beck-Sickinger AG, Gray WP. Neuropeptide Y stimulates neuronal precursor proliferation in the post-natal and adult dentate gyrus. J Neurochem. 2005; 93:560-570. [PubMed: 15836615]

Howell OW, Scharfman HE, Herzog H, Sundstrom LE, Beck-Sickinger A, Gray WP. Neuropeptide Y is neuroproliferative for post-natal hippocampal precursor cells. J Neurochem. 2003; 86:646-659. [PubMed: 12859678]

Kawauchi S, Beites CL, Crocker CE, Wu HH, Bonnin A, Murray R, Calof AL. Molecular signals regulating proliferation of stem and progenitor cells in mouse olfactory epithelium. Dev Neurosci. 2004; 26:166-180. [PubMed: 15711058]

Mackay-Sim A, Chuah MI. Neurotrophic factors in the primary olfactory pathway. Prog Neurobiol. 2000; 62:527-559. [PubMed: 10869782]

Mathieu M, Tagliafierro G, Bruzzone F, Vallarino M. Neuropeptide tyrosine-like immunoreactive system in the brain, olfactory organ and retina of the zebrafish, Danio rerio, during development. Brain Res Dev Brain Res. 2002; 139:255-265.

Milenkovic I, Weick M, Wiedemann P, Reichenbach A, Bringmann A. Neuropeptide Y-evoked proliferation of retinal glial (Muller) cells. Graefes Arch Clin Exp Ophthalmol. 2004; 242:944950. [PubMed: 15293057]

Miyawaki A, Homma H, Tamura H, Matsui M, Mikoshiba K. Zonal distribution of sulfotransferase for phenol in olfactory sustentacular cells. EMBO J. 1996; 15:2050-2055. [PubMed: 8641270]

Montani G, Tonelli S, Elsaesser R, Paysan J, Tirindelli R. Neuropeptide Y in the olfactory microvillar cells. Eur J Neurosci. 2006; 24:20-24. [PubMed: 16800866] 
Mousley A, Polese G, Marks NJ, Eisthen HL. Terminal nerve-derived neuropeptide y modulates physiological responses in the olfactory epithelium of hungry axolotls (Ambystoma mexicanum). $\mathrm{J}$ Neurosci. 2006; 26:7707-7717. [PubMed: 16855098]

Murdoch B, Roskams AJ. A novel embryonic nestin-expressing radial glia-like progenitor gives rise to zonally restricted olfactory and vomeronasal neurons. J Neurosci. 2008; 28:4271-4282. [PubMed: 18417707]

Neary JT, Rathbone MP, Cattabeni F, Abbracchio MP, Burnstock G. Trophic actions of extracellular nucleotides and nucleosides on glial and neuronal cells. Trends Neurosci. 1996; 19:13-18. [PubMed: 8787135]

Ralevic V, Burnstock G. Receptors for purines and pyrimidines. Pharmacol Rev. 1998; 50:413-492. [PubMed: 9755289]

Rathbone MP, Christjanson L, Deforge S, Deluca B, Gysbers JW, Hindley S, Jovetich M, Middlemiss P, Takhal S. Extracellular purine nucleosides stimulate cell division and morphogenesis: pathological and physiological implications. Med Hypotheses. 1992a; 37:232-240. [PubMed: 1625599]

Rathbone MP, Deforge S, Deluca B, Gabel B, Laurenssen C, Middlemiss P, Parkinson S. Purinergic stimulation of cell division and differentiation: mechanisms and pharmacological implications. Med Hypotheses. 1992b; 37:213-219. [PubMed: 1625596]

Rathbone MP, Middlemiss PJ, Gysbers JW, Andrew C, Herman MA, Reed JK, Ciccarelli R, Di Iorio P, Caciagli F. Trophic effects of purines in neurons and glial cells. Prog Neurobiol. 1999; 59:663690. [PubMed: 10845757]

Reimer M, Moller K, Sundler F, Hannibal J, Fahrenkrug J, Kanje M. Increased expression, axonal transport and release of pituitary adenylate cyclase-activating polypeptide in the cultured rat vagus nerve. Neuroscience. 1999; 88:213-222. [PubMed: 10051202]

Ressler KJ, Sullivan SL, Buck LB. A zonal organization of odorant receptor gene expression in the olfactory epithelium. Cell. 1993; 73:597-609. [PubMed: 7683976]

Rieger A, Deitmer JW, Lohr C. Axon-glia communication evokes calcium signaling in olfactory ensheathing cells of the developing olfactory bulb. Glia. 2007; 55:352-359. [PubMed: 17136772]

Schwob JE. Neural regeneration and the peripheral olfactory system. Anat Rec. 2002; 269:33-49. [PubMed: 11891623]

Skabo SJ, Holloway AF, West AK, Chuah MI. Metallothioneins 1 and 2 are expressed in the olfactory mucosa of mice in untreated animals and during the regeneration of the epithelial layer. Biochem Biophys Res Commun. 1997; 232:136-142. [PubMed: 9125117]

Stanic D, Paratcha G, Ledda F, Herzog H, Kopin AS, Hokfelt T. Peptidergic influences on proliferation, migration, and placement of neural progenitors in the adult mouse forebrain. Proc Natl Acad Sci U S A. 2008; 105:3610-3615. [PubMed: 18305161]

Ubink R, Halasz N, Zhang X, Dagerlind A, Hokfelt T. Neuropeptide tyrosine is expressed in ensheathing cells around the olfactory nerves in the rat olfactory bulb. Neuroscience. 1994; 60:709-726. [PubMed: 7936197]

Ubink R, Hokfelt T. Expression of neuropeptide Y in olfactory ensheathing cells during prenatal development. J Comp Neurol. 2000; 423:13-25. [PubMed: 10861533]

Vassar R, Ngai J, Axel R. Spatial segregation of odorant receptor expression in the mammalian olfactory epithelium. Cell. 1993; 74:309-318. [PubMed: 8343958]

Whitby-Logan GK, Weech M, Walters E. Zonal expression and activity of glutathione S-transferase enzymes in the mouse olfactory mucosa. Brain Res. 2004; 995:151-157. [PubMed: 14672804] 

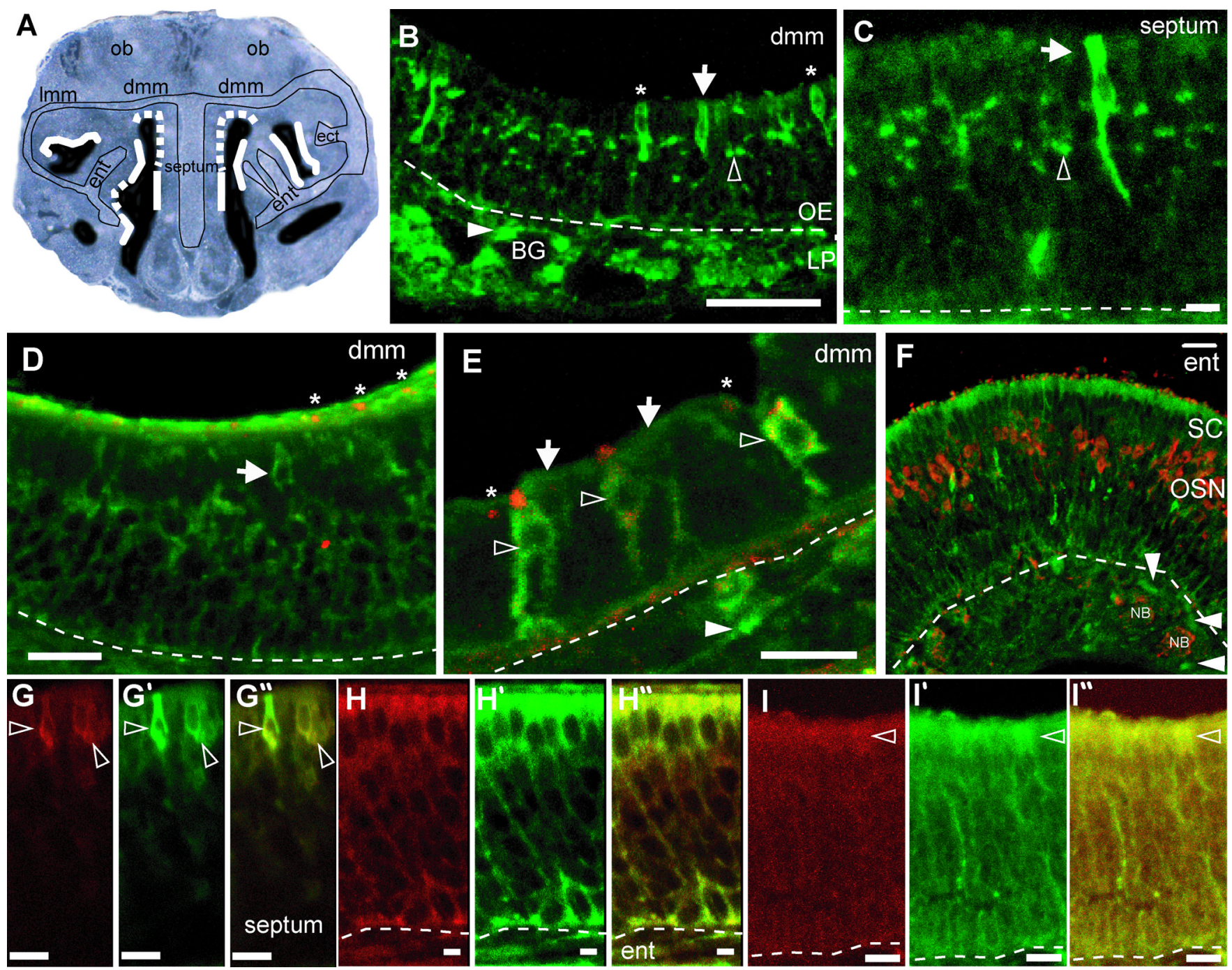

Figure 1. NPY expression in neonatal mouse olfactory epithelium

A: Coronal neonatal OE cryosection $(20 \mu \mathrm{m})$ with overlays depicting the areas where intense (dotted lines) and diffuse (solid lines) NPY immunoreactivity (IR) is seen. Note that in this section, the left endoturbinate was not present. Black lines indicate where cartilage is located. Abbreviations: dmm, dorsal medial meatus, $1 \mathrm{~mm}$, lateral medial meatus, ob, olfactory bulb, ent, endoturbinate, ect, ectoturbinate. B,C: Z stack images from the dmm and septum showing intense NPY-IR in cells morphologically similar to microvillar cells (asterisk) and sustentacular cells (arrow) in the apical region of the OE, in cell processes and the basal portion of the cell soma (open triangles), and in Bowman's gland duct cells of the lamina propria (solid triangles). Dashed line = basement membrane. LP, lamina propria; $\mathrm{OE}$, olfactory epithelium; BG, Bowman's glands. D,E: Z stack images from the dmm showing NPY (green) and PLC $\beta 2$ (red) IR. PLC $\beta 2^{+} \mathrm{NPY}^{-}$microvillar cells (*); $\mathrm{PLC} 2^{+} \mathrm{NPY}^{+}$ microvillar cells (open triangle); $\mathrm{PLC} \beta 2^{-} \mathrm{NPY}^{+}$cells (arrow); $\mathrm{NPY}^{+}$olfactory ensheathing glia (OEG; solid triangle). F: Z stack image showing immunoreactivity to anti-olfactory marker protein (OMP; red) and anti-NPY (green) from the OE of an endoturbinate. OMP-IR was seen in OSNs. NPY-IR was not observed in OMP immunoreactive cells. NPY ${ }^{+}$OEG (solid triangle) surround $\mathrm{OMP}^{+}$nerve bundles. SC, sustentacular cell layer; OSN, olfactory sensory neuron layer; NB, nerve bundle. G-H: NPY- (green) and calnexin- (red) IR in sustentacular cells (open triangles). I: NPY- (green) and Notch 2- (red) IR in sustentacular 
cells (open triangles). Scale bars: $\mathrm{B}=50 \mu \mathrm{m} ; \mathrm{C}, \mathrm{F}=10 \mu \mathrm{m} ; \mathrm{D}=30 \mu \mathrm{m} ; \mathrm{E}, \mathrm{I}=20 \mu \mathrm{m} ; \mathrm{G}=$ $15 \mu \mathrm{m} ; \mathrm{H}=7.5 \mu \mathrm{m}$. 


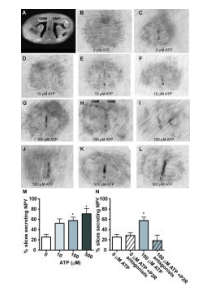

Figure 2. ATP evokes release of NPY via purinergic receptor activation

A: Coronal $500 \mu \mathrm{m}$ slice from the nose of a neonatal mouse. Olfactory epithelial (OE) regions of the slice include the dorsal medial meatus (DMM), turbinate (T) and the septum (S), as outlined on the right side (dashed line). Representative examples of NPY immunoreactivity on nitrocellulose observed after $1 \mathrm{hr}$ in the absence (B,C), and presence of 10 (D-F), 100 (G-I) and $500 \mu \mathrm{M}$ (J-L) ATP. M, N: Nitrocellulose blots were counted for number of slices with NPY immunoreactivity that were treated with (M) ATP $(0-500 \mu \mathrm{M} ; \mathrm{n}$ $=82,41,37,20$ slices from $\mathrm{n}=10,6,6,4$ animals, respectively) and (N) Purinergic receptor (P2R) antagonists $(\mathrm{n}=82,43,37,29$ slices from $\mathrm{n}=10,5,6,4$ animals, respectively). Data are significant at $\mathrm{p}=0.001(\mathbf{M})$ and $\mathrm{p}=0.004(\mathbf{N})$ (one way ANOVA). *, $\mathrm{p}<0.05$ compared to $0 \mu \mathrm{M}$ ATP (Tukey's post-hoc test). 


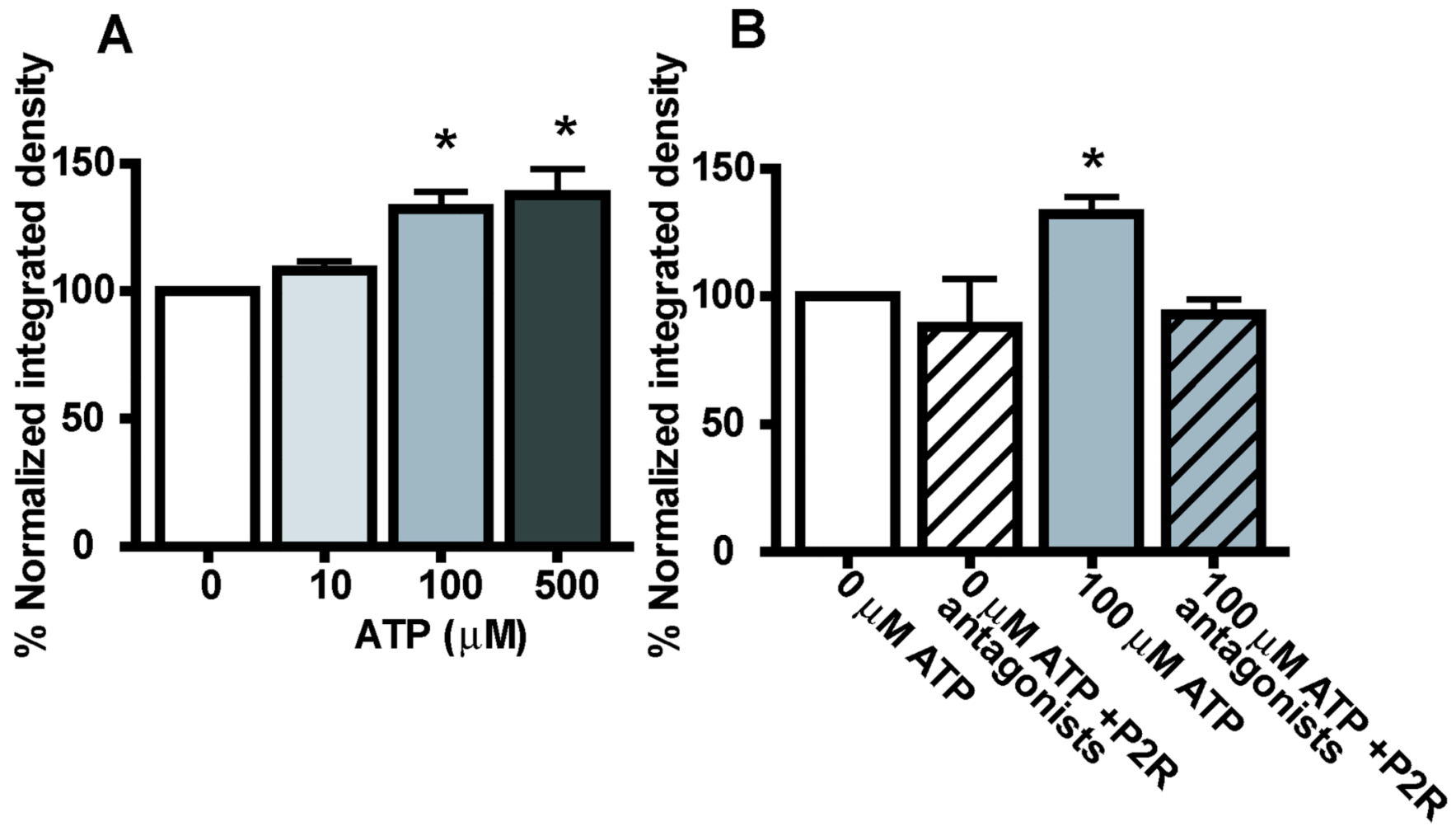

Figure 3. Quantification of ATP-induced NPY release using the visualization assay Integrated densities were measured from nitrocellulose blots processed for NPYimmunoreactivity following exposure to OE slices and (A) ATP $(0-500 \mu \mathrm{M} ; \mathrm{n}=82,41,37$, 20 slices respectively from $\mathrm{n}=10,6,6,4$ animals, respectively; $\mathrm{p}<0.0001$, one way ANOVA) and/or (B) purinergic receptor (P2R) antagonists $(n=82,43,37,29$ slices from $n$ $=10,5,6,4$ animals; $\mathrm{p}<0.007$, one way ANOVA). (A)*, p<0.05 v. 0 and $10 \mu \mathrm{M} \mathrm{ATP}$ (Tukey's post-hoc test). (B) $*$, p $<0.05$ v. $0 \mu \mathrm{M}$ ATP \pm P2R antagonists and $100 \mu \mathrm{M}$ ATP + $\mathrm{P} 2 \mathrm{R}$ antagonists (Tukey's post-hoc test). 

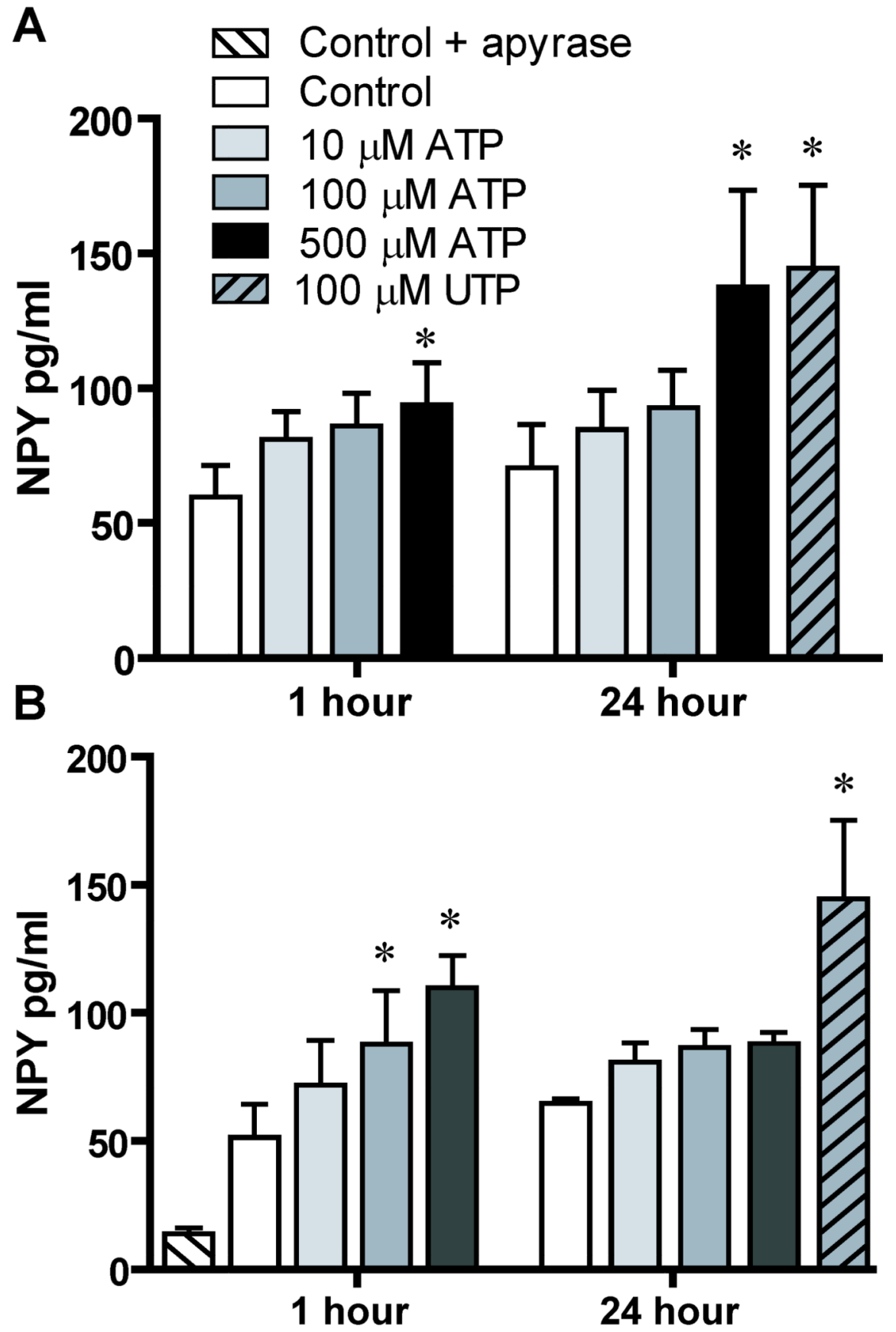

Figure 4. Quantification of ATP-induced NPY release using immunoassays OE slices were cultured in $3 \mathrm{U} / \mathrm{ml}$ apyrase, or 0 (control), 10, 100, or $500 \mu \mathrm{M}$ ATP, or 100 $\mu \mathrm{M}$ UTP for 1 or $24 \mathrm{hrs}$, and the media was assayed for NPY levels by (A) radioimmunoassay $(n=30-48$ slices from 5-8 animals each treatment) and $(B)$ enzyme immunoassay $\left(\mathrm{n}=24-32\right.$ slices from 3-5 animals each treatment). ${ }^{*}, \mathrm{p}<0.05 \mathrm{v}$. control 0 $\mu$ M ATP (Tukey's post-hoc test). Values for the RIA data (A) not presented in text: control, 10,100 , and $500 \mu \mathrm{M}$ ATP evoked $59 \pm 12,81 \pm 11,86 \pm 12$, and $94 \pm 16 \mathrm{pg} / \mathrm{ml} \mathrm{NPY}$ secretion after $1 \mathrm{hr}$, respectively $(\mathrm{n}=\sim 30$ slices from 8 animals in each treatment) and $70 \pm$ $16,84 \pm 15,93 \pm 14$, and $137 \pm 36 \mathrm{pg} / \mathrm{ml}$ after $24 \mathrm{hr}$, respectively $(\mathrm{n}=\sim 30$ slices from 5 animals in each treatment). 


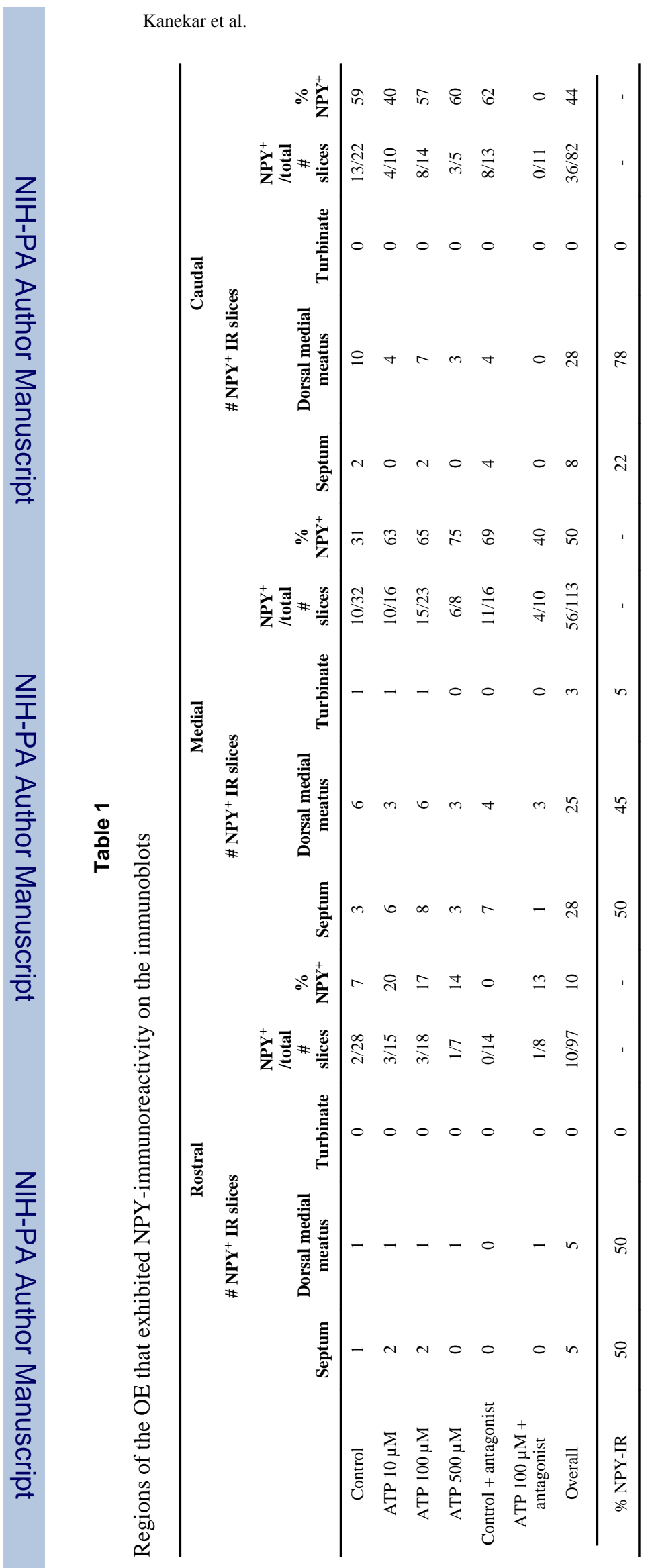

Page 18

J Neurosci Res. Author manuscript; available in PMC 2011 May 19. 